\title{
A Modified Mutation Detection Method for Large-scale Cloning of the Possible Single Nucleotide Polymorphism Sequences
}

\author{
Ming-Chung Jiang*, Pao-Chu Jiang, Ching-Fong Liao and Ching-Chiu Lee \\ Institute of Zoology, Academia Sinica, Taipei, Taiwan ROC
}

Received 22 October 2004, Accepted 17 November 2004

\begin{abstract}
Although the human genome has been nearly completely sequenced, the functions and the roles of the vast majority of the genes, and the influences of single nucleotide polymorphisms (SNPs) in these genes are not entirely known. A modified mutation detection method was developed for large-scale cloning of the possible SNPs between tumor and normal cells for facilitating the identification of genetic factors that associated with cancer formation and progression. The method involves hybridization of restriction enzyme-cut chromosomal DNA, cleavage and modification of the sites of differences by enzymes, and differential cloning of sequence variations with a designed vector. Experimental validations of the presence and location of sequence variations in the isolated clones by PCR and DNA sequencing support the capability of this method in identifying sequence differences between tumor cells and normal cells.
\end{abstract}

Keywords: Differential cloning, Genome, Normal cells, Single nucleotide polymorphisms, Tumor cells

\section{Introduction}

Sequence variations in the human genome, including mutations, translocations, amplifications, insertions and deletions, may alter the functions of genes and predispose an individual to disease formation (Sinden et al., 1992). SNPs are the most frequent type of sequence variation in the human genome. SNPs in the protein-coding regions of genes may alter the functions of the coded proteins. SNPs in the regulatory regions of genes may influence the expression of the coding proteins. SNPs may themselves represent genetic variants that affect disease susceptibility or progression. Most SNPs are found in non-coding regions of the genome, and have no

*To whom correspondence should be addressed.

Tel: 886-2-27899533; Fax: 886-2-27858059

E-mail: jiangmcedu@yahoo.com.tw direct known function in individuals. But these SNPs (also the SNPs in protein-coding regions and regulatory regions) may be used as genetic markers to detect association between a particular genomic region and the disease for discovering genetic factors in diseases (Goodstadt and Ponting, 2000; Becker et al., 2003). The association study can use information from a relatively small set of variants that capture most of the common patterns of variation in the genome, any region or gene can be tested for association with a particular disease (The International HapMap Consortium, 2003).

Identification and genotyping a vast number of genetic polymorphisms in large populations are increasingly important for disease gene identification, pharmacogenetics and population-based studies (Cantor, 1999; Elahi et al., 2004; Nelson et al., 2004). Most of the current employed SNP detection methods use allele-specific probes or polymerase chain reaction (PCR) and designed primers to detect SNPs (sequence variations) of specified sequences (Mir and Southern, 2000; Chen et al., 2003; Kwok, 2003). The differential cloning method described herein is aimed to clone the possible SNPs between tumor cells and normal cells at a large-scale to facilitate the discovery of genetic factors that associated with tumor formation and progression. The strategy of this method is described clearly in the text.

\section{Materials and Methods}

Cells and enzymes Human cell lines derived from hepatoma, the Hep G2 cells, and from normal liver, the Chang liver cells, were used in the experiments. Both cells were from the American Type Culture Collection (Manassas, Virginia, USA) and were grown in DMEM medium as described previously (Jiang and Liao, 2004). Nuclease S1 was from Invitrogen (Carlsbad, California, USA) and other enzymes were from New England Biolabs (Beverly, Massachusetts, USA).

DNA precipitation Ethanol precipitation of DNA described in this section was performed by adding 0.1 volume of $3 \mathrm{M}$ sodium acetate $(\mathrm{pH} 7.0)$ and 1.5 volumes of cold $\left(-20^{\circ} \mathrm{C}\right)$ absolute ethanol 
to a $200-\mu \mathrm{l}$ DNA solution in a $0.5-\mathrm{ml}$ microcentrifuge tube, mixing this completely, incubating the tube at $-70^{\circ} \mathrm{C}$ for $30 \mathrm{~min}$, liquefying the frozen sample with fingers, centrifuging the tube at $14,000 \mathrm{rpm}$ at $4^{\circ} \mathrm{C}$ for $20 \mathrm{~min}$, briefly rinsing the DNA pellet with cold $\left(-20^{\circ} \mathrm{C}\right)$ $75 \%$ ethanol, centrifuging the tube at $14,000 \mathrm{rpm}$ at $4^{\circ} \mathrm{C}$ for $1 \mathrm{~min}$, removing the ethanol, centrifuging the tube at $14,000 \mathrm{rpm}$ at $4^{\circ} \mathrm{C}$ for $0.5 \mathrm{~min}$ to spin down the ethanol in the wall, removing the ethanol with a mini-tip, drying the DNA pellet at $50^{\circ} \mathrm{C}$ for $5 \mathrm{~min}$, and dissolving the DNA pellet in $\mathrm{H}_{2} \mathrm{O}$ at $4^{\circ} \mathrm{C}$ overnight. The DNA pellet may become transparent; avoid DNA loss when removing the ethanol.

Preparation of chromosomal DNA Chromosomal DNA was extracted as described (Sambrook et al., 1989). The chromosomal DNA was incubated in Tsp509I buffer (10 mM Bis Tris Propane$\mathrm{HCl}, \mathrm{pH} 7.0,10 \mathrm{mM} \mathrm{MgCl}_{2}, 1 \mathrm{mM}$ DTT) containing $1.5 \mathrm{U} / \mu \mathrm{g}$ Tsp509I at $65^{\circ} \mathrm{C}$ for $4 \mathrm{~h}$. During incubation, the sample was pipetted with a 1-ml tip and centrifuged briefly every $30 \mathrm{~min}$. The DNA fragments were extracted twice with phenol/chloroform and once with chloroform/isoamyl alcohol, and were then precipitated with ethanol.

Dephosphorylation of $\boldsymbol{T}$ sp509I-generated DNA fragments $T s p 509 \mathrm{I}-$ cleaved DNA was incubated in dephosphorylation buffer $((10 \mathrm{mM}$ Tris- $\mathrm{HCl}, \mathrm{pH} 8.3,0.1 \mathrm{mM} \mathrm{ZnCl} 2,1 \mathrm{mM} \mathrm{MgCl}$, and $0.5 \mathrm{U} / \mu \mathrm{g}$ calf intestinal alkaline phosphatase (CIP)) at $37^{\circ} \mathrm{C}$ for $70 \mathrm{~min}$. During incubation, the tube was vortexed and centrifuged briefly every $25 \mathrm{~min}$. Dephosphorylation was stopped by incubating the reaction mixture in proteinase $\mathrm{K}$ buffer $(0.3 \%$ SDS, $5 \mathrm{mM}$ EDTA, $\mathrm{pH}$ 8.0, and $100 \mu \mathrm{g} / \mathrm{ml}$ proteinase $\mathrm{K}$ ) at $50^{\circ} \mathrm{C}$ for $30 \mathrm{~min}$. DNA was extracted 3 times with phenol/chloroform and once with chloroform/ isoamyl alcohol, and was then precipitated with ethanol.

Ligation with EcoR1 adaptors EcoR1 adaptors were prepared by mixing equal molar quantities of the oligonucleotides, 5'AAGGGGTTCG-3', and 5'-P-AATTCGAACCCCTT-3'. The oligonucleotide mixture was heated at $95^{\circ} \mathrm{C}$ for $5 \mathrm{~min}$ and cooled at room temperature for $30 \mathrm{~min}$ and was then precipitated with ethanol. Dephosphorylated DNA fragments $(20 \mu \mathrm{g})$ were incubated with 6-fold excess moles of EcoR1 adaptors in T4 DNA ligation buffer (50 mM Tris- $\mathrm{HCl}$, pH 7.5, $10 \mathrm{mM} \mathrm{MgCl}_{2}, 10 \mathrm{mM}$ DTT, $1 \mathrm{mM}$ ATP, $25 \mu \mathrm{g} / \mathrm{ml} \mathrm{BSA}$, and 5,000 U T4 DNA ligase) at $4^{\circ} \mathrm{C}$ for $12 \mathrm{~h}$ in a total volume of $100 \mu \mathrm{l}$. Another 5,000 U T4 DNA ligase was added to the ligation buffer, and the tube was incubated at 16 ${ }^{\circ} \mathrm{C}$ for another $8 \mathrm{~h}$. During incubation, the tube was vortexed and centrifuged briefly every hour. DNA was extracted with phenol/ chloroform and chloroform/isoamyl alcohol and was then precipitated with ethanol.

Repair of nicks Nicks in the DNA fragments were repaired by incubating the DNA in E. coli DNA polymerase I buffer $(10 \mathrm{mM}$ Tris-HCl, pH 7.5, $5 \mathrm{mM} \mathrm{MgCl}_{2}, 7.5 \mathrm{mM}$ DTT, $5 \mathrm{mM}$ dNTP, and 50 $\mathrm{U}$ E. coli DNA polymerase I) at $16^{\circ} \mathrm{C}$ for $70 \mathrm{~min}$ in a total volume of $50 \mu \mathrm{l}$. During incubation, the tube was vortexed and centrifuged briefly every $10 \mathrm{~min}$. DNA fragments were extracted with phenol/ chloroform and chloroform/isoamyl alcohol, followed by ethanol precipitation. DNA was then incubated in T4 DNA ligation buffer containing 4,000 U T4 DNA ligase at $4^{\circ} \mathrm{C}$ for $12 \mathrm{~h}$ in a total volume of $50 \mu \mathrm{l}$. Another 4,000 U T4 DNA ligase was added to the ligation buffer and the tube was incubated at $16^{\circ} \mathrm{C}$ for another $6 \mathrm{~h}$. During incubation, the tube was vortexed and centrifuged briefly every hour. DNA fragments were extracted with phenol/chloroform and chloroform/isoamyl alcohol, followed by ethanol precipitation.

Preparation of heteroduplex and homoduplex fragments Each Hep G2 and Chang liver DNA fragment was divided into 4 equal fractions. Heteroduplex fragments were prepared by mixing 1 fraction each of the Hep G2 and Chang liver DNA fragments. Homoduplex fragments were prepared by mixing 2 fractions of the Chang liver DNA fragment. Each DNA fragment mixture was suspended in hybridization buffer $(35 \mathrm{mM}$ Tris- $\mathrm{HCl}, \mathrm{pH}$ 7.6, 300 $\mathrm{mM} \mathrm{NaCl}$, and $3.5 \mathrm{mM} \mathrm{MgCl}_{2}$ ) in a total volume of $150 \mu \mathrm{l}$ in a microcentrifuge tube with a screw cap to avoid evaporation. The tubes were boiled for $5 \mathrm{~min}$ and were placed immediately in a hybridization oven with constant slow rolling at $68^{\circ} \mathrm{C}$ for $24 \mathrm{~h}$. The tubes were cooled at room temperature for $30 \mathrm{~min}$, and the DNA was harvested by ethanol precipitation.

T7 endonuclease I treatment For T7 endonuclease I treatment, each $15 \mu \mathrm{g}$ of heteroduplex and homoduplex fragments was separately incubated in T7 endonuclease I buffer $(20 \mathrm{mM}$ Trisacetate, $\mathrm{pH} 7.9,50 \mathrm{mM}$ potassium acetate, $10 \mathrm{mM}$ magnesium acetate, $1 \mathrm{mM}$ DTT, and $7.5 \mathrm{U} \mathrm{T} 7$ endonuclease I) at $37^{\circ} \mathrm{C}$ for 30 min in a total volume of $50 \mu \mathrm{l}$. DNA was extracted with phenol/ chloroform and chloroform/isoamyl alcohol, followed by ethanol precipitation.

Nuclease S1 treatment After T7 endonuclease I treatment, the DNA was incubated in nuclease $\mathrm{S} 1$ buffer $(30 \mathrm{mM}$ sodium acetate, $\mathrm{pH}$ 5.2, $1 \mathrm{mM} \mathrm{ZnSO}_{4}, 5 \%$ (v/v) glycerol, $300 \mathrm{mM} \mathrm{NaCl}$, and $22 \mathrm{U}$ nuclease $\mathrm{S} 1$ ) at $37^{\circ} \mathrm{C}$ for $10 \mathrm{~min}$ in a total volume of $50 \mu \mathrm{l}$. The DNA was extracted twice with phenol/chloroform and once with chloroform/isoamyl alcohol and was then precipitated with ethanol.

T4 DNA polymerase treatment Following nuclease $\mathrm{S} 1$ treatment, the DNA was incubated in T4 DNA polymerase buffer $(10 \mathrm{mM}$ Tris-HCl, pH 7.9, $50 \mathrm{mM} \mathrm{NaCl}, 10 \mathrm{mM} \mathrm{MgCl} 2,1 \mathrm{mM}$ DTT, 100 $\mu \mathrm{M} \mathrm{dNTP}, 50 \mu \mathrm{g} / \mathrm{ml} \mathrm{BSA}$, and $4.5 \mathrm{U}$ T4 DNA polymerase) at $12^{\circ} \mathrm{C}$ for $15 \mathrm{~min}$ in a total volume of $30 \mu \mathrm{l}$. During incubation, the tube was vortexed and centrifuged briefly every $15 \mathrm{~min}$. The DNA was extracted with phenol/chloroform and chloroform/isoamyl alcohol, followed by ethanol precipitation.

Removal of the $\boldsymbol{E c o R} 1$ adaptors by $\boldsymbol{T}$ sp509I digestion After T4 DNA polymerase treatment, the DNA was incubated in Tsp509I buffer containing $10 \mathrm{U} \mathrm{Tsp509I}$ at $65^{\circ} \mathrm{C}$ for $70 \mathrm{~min}$ in a total volume of $20 \mu \mathrm{l}$. During incubation, the tube was vortexed and centrifuged briefly every $30 \mathrm{~min}$. The DNA sample was extracted with phenol/ chloroform and chloroform/isoamyl alcohol, followed by ethanol precipitation. Although the free $E c o$ R 1 adaptors are unable to be cloned with the vectors, the EcoR1 ends of these adaptors still can ligate into the $E c o \mathrm{R} 1$ ends of the vectors. Thus, removing the free $E c o$ R1 adaptors with commercial nucleotide removing kit that removes nucleotides smaller than $15 \mathrm{bp}$, and then reducing the volume of the DNA sample by ethanol precipitation before ligation, should be able to increase the cloning efficiency of the duplex DNA 
fragments. If the free adaptors are removed with a small nucleotide removing kit, then there is no need to dephosphrylate the blunt ends (i.e. the SmaI-cut ends) of the cloning vectors.

Preparation of vector The pUC 19 plasmids were incubated in Sma I buffer $(20 \mathrm{mM}$ Tris-acetate, $\mathrm{pH} 7.9,50 \mathrm{mM}$ potassium acetate, $10 \mathrm{mM}$ magnesium acetate, $1 \mathrm{mM}$ DTT, and $1.5 \mathrm{U} / \mu \mathrm{g}$ Sma I) at $25^{\circ} \mathrm{C}$ for $1.5 \mathrm{~h}$. The DNA was extracted with phenol/ chloroform and chloroform/isoamyl alcohol, followed by ethanol precipitation. The DNA was then dephosphorylated in dephosphorylation buffer containing $0.6 \mathrm{U} / \mu \mathrm{g} \mathrm{CIP}$ at $37^{\circ} \mathrm{C}$ for 20 $\min$ and at $55^{\circ} \mathrm{C}$ for another $55 \mathrm{~min}$. Dephosphorylation was stopped by incubating the reaction mixture in proteinase $\mathrm{K}$ buffer containing $100 \mu \mathrm{g} / \mathrm{ml}$ proteinase $\mathrm{K}$ at $50^{\circ} \mathrm{C}$ for $30 \mathrm{~min}$. DNA was extracted 3 times with phenol/chloroform and once with chloroform/ isoamyl alcohol and was precipitated with ethanol. The DNA was then incubated in EcoRI buffer (100 mM Tris-HCl, pH 7.0, $50 \mathrm{mM}$ $\mathrm{NaCl}, 10 \mathrm{mM} \mathrm{MgCl}, 0.025 \%$ Triton X-100, and $1.5 \mathrm{U} / \mu \mathrm{g}$ EcoRI) at $37^{\circ} \mathrm{C}$ for $1.5 \mathrm{~h}$. The DNA was resolved on a $1.5 \%$ agarose gel, and the vector DNA band was eluted.

Test ligation Test ligation was done by ligating a small aliquot of the vectors with the EcoRI adapter that possessed two phosphorylated ends. The ligation mixture was transformed into high efficiency XL1-Blue competent cells. Both white colonies and blue colonies were observed in plates containing IPTG, X-gal, ampicillin, and tetracycline, and $65 \%$ of the colonies were white. The plates of the control ligation only grew blue colonies. The control ligation contained the same materials as in the test ligation but without the addition of the EcoRI adapter.

Cloning of sequence variations The DNA fragments were incubated in T4 DNA ligation buffer containing $0.1 \mu \mathrm{g}$ of SmaI/ CIP/EcoRI-treated pUC 19 vectors and $50 \mathrm{U} / \mu 1 \mathrm{~T} 4$ DNA ligase at $16^{\circ} \mathrm{C}$ for $16 \mathrm{~h}$. The ligation mixture was transformed into high efficiency XL1-Blue competent cells, and cells were spread on plates containing IPTG, X-gal, ampicillin, and tetracycline. Sequences of the inserts were identified by BLAST in NCBI.

PCR PCR reactions were done as described previously (Jiang and Liao, 2004). The PCR-amplified bands were eluted and cloned into pGEM-T-easy vectors (Promega Madison, USA). The identities of the PCR products were demonstrated by DNA sequencing.

\section{Results and Discussion}

The strategy of the method is outlined in Fig. 1. Human cell lines derived from hepatoma, the Hep G2 cells, and from normal liver, the Chang liver cells, were used as an example for large-scale cloning of the possible SNPs between a tumor cells and a normal cells. Chromosomal DNA extracted from cells were cleaved with the restriction enzyme, Tsp509I. Tsp509I recognizes the sequence, AATT, which is a very common sequence in mammalian genomes. Tsp509I digestion generated DNA fragments ranging from about 20 to $1,500 \mathrm{bp}$, and the most abundant were those around $200 \mathrm{bp}$ in length (Fig. 2).
The ends of the Tsp509I-cleaved DNA fragments were dephosphorylated with CIP to suppress self-ligation before these ends were ligated with the EcoR1 adaptors. Ligation of two DNA fragments involves the formation of new bonds between phosphate residues located at the 5 ' termini of double-stranded DNA and the adjacent 3'-hydroxyl moieties; therefore there were two single-strand nicks in each DNA fragment after ligation of the CIP-treated DNA with the EcoR1 adaptors. Escherichia coli DNA polymerase I is a DNA-dependent DNA polymerase with inherent $5^{\prime}$ to $3^{\prime}$ exonuclease, $3^{\prime}$ to $5^{\prime}$ exonuclease, and 5' to $3^{\prime}$ polymerase activities (Kelley and Stump, 1979). Thus, E. coli DNA polymerase I was used to remove the dephosphorylated 5' termini and to repair the nicks in the EcoR1 adaptor-ligated DNA fragments. The $3^{\prime}$ to 5 ' exonuclease activity of $E$. coli DNA polymerase I may produce nicks in the DNA (Sambrook et al., 1989). Thus, nicks in the DNA fragments were repaired with T4 DNA ligase.

Heteroduplex fragments were prepared by melting and reannealing Hep G2 DNA fragments with equal amounts of Chang liver DNA fragments. Homoduplex fragments were prepared by melting and re-annealing Chang liver DNA fragments. The homoduplex fragments were used as the control in the experiments. The duplex DNA fragments were treated with the resolvase, $\mathrm{T} 7$ endonuclease $\mathrm{I}$, at a concentration of $7.5 \mathrm{U} /$ reaction to scan the mismatched base pairs in the hybrids.

Resolvase has been shown to cleave single-base-pair mismatches in model experiments with synthetic DNA (Kosak and Kemper, 1990). With the use of designed primers and the PCR technique, the two most extensively studied resolvases, T7 endonuclease I and T4 endonuclease VII, are widely employed in the detection of mutations of many known genes (Mashal et al., 1995; Youil et al., 1995). Resolvase can detect all eight types of mismatches (A/A, T/T, $\mathrm{C} / \mathrm{C}, \mathrm{G} / \mathrm{G}, \mathrm{A} / \mathrm{C}, \mathrm{A} / \mathrm{G}, \mathrm{T} / \mathrm{C}$, and T/G) as well as insertions and deletions (Kleff and Kemper, 1988; Solaro et al., 1993). Resolvase binds to non-perfectly matched DNA and then cleaves it within six nucleotides $3^{\prime}$ or 5', respectively. A counter-nick may then be placed on the other side of the mismatch within six nucleotides on the opposite-strand DNA. The rates and frequencies of the formations of these two nicks are not necessarily the same, and the locations of these two nicks on the DNA are not necessarily symmetrical about the mismatch. Thus, both single-strand nicks and staggered double-strand breaks may be observed after T7 endonuclease I or T4 endonuclease VII digestion (Parsons and Kemper, 1990, Parkinson and Lilley, 1997).

Nuclease S1 can induce double-strand breaks in DNA nicks as well as being capable of hydrolyzing single-stranded DNA (Chaudhry and Weinfeld, 1995). Thus, the T7 endonuclease Itreated DNA was treated with nuclease S1 (22 U/reaction) at $37^{\circ} \mathrm{C}$ for $10 \mathrm{~min}$ to induce double-strand breaks in DNA nicks generated by $\mathrm{T} 7$ endonuclease I and also to hydrolyze singlestranded regions of the staggered double-strand breaks 


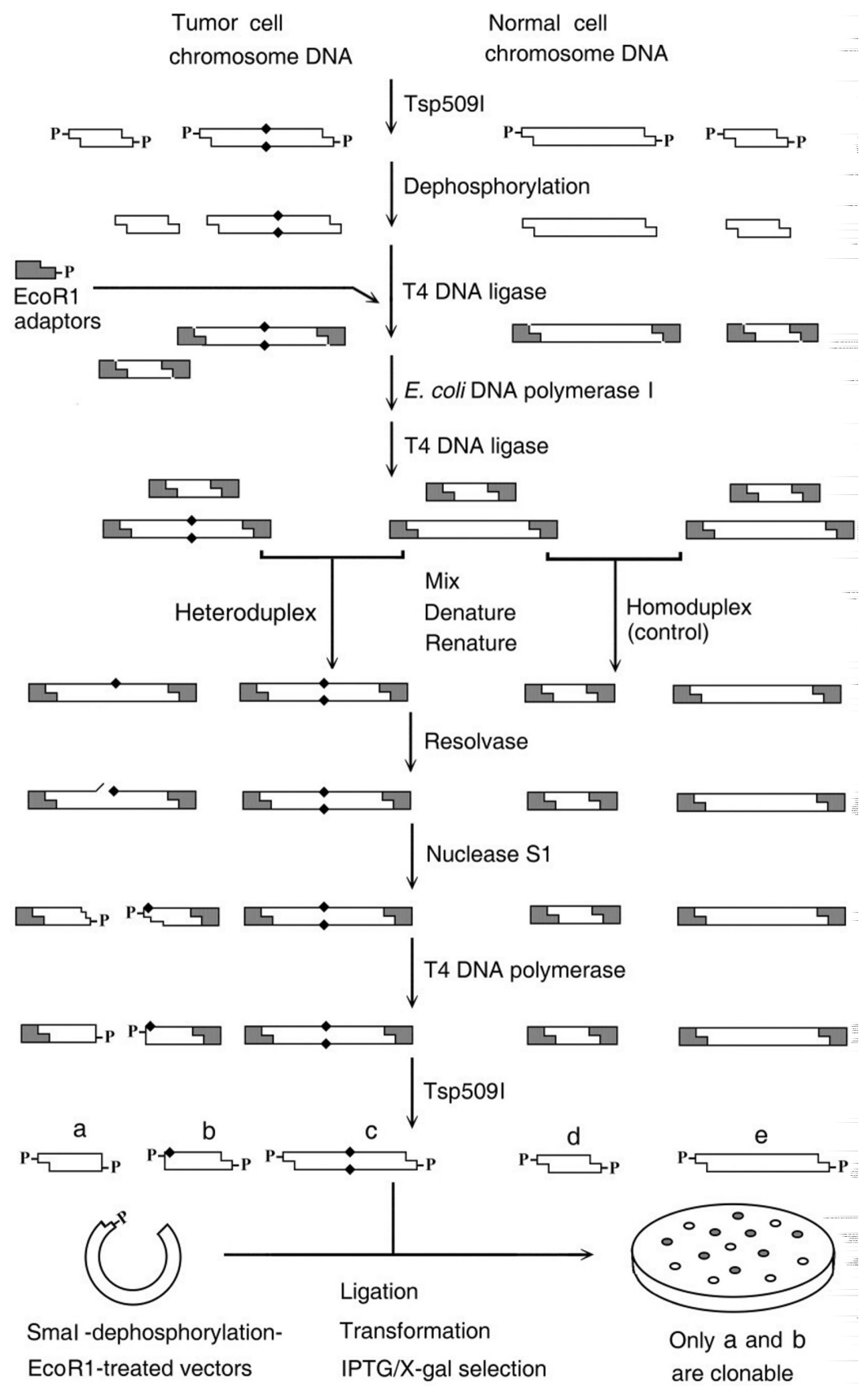

Fig. 1. Strategy for large-scale cloning of the possible single nucleotide polymorphism sequences between a tumor cell line and a normal cell line. Chromosomal DNA was cleaved with Tsp509I or its isoschizomers. The DNA fragments were dephosphorylated and ligated with the EcoRI adaptors. Nicks between adaptors and DNA fragments were repaired by E. coli DNA polymerase I and T4 DNA ligase. The heteroduplex fragments were prepared by melting and re-annealing DNA fragments of two cell lines. The homoduplex fragments were prepared by melting and re-annealing DNA fragments of a single cell line. The duplex fragments were scanned for mismatches by resolvase. Resolvase produces nicks or staggered double-strand breaks within 6 nucleotides around the mismatches. Nuclease S1 and T4 DNA polymerase treatment creates ligatable blunt DNA ends at the nicks or the breaks. The EcoR1 adaptors in duplex fragments were cleaved with Tsp509I digestion. Each duplex fragment containing SNP now possesses a phosphorylated blunt end and a phosphorylated EcoR1 compatible cohesive end and thus can be cloned with the SmaI-dephosphorylation-EcoR1-treated vectors. Each normal duplex fragment now possesses only two phosphorylated EcoR1-compatible cohesive ends and thus cannot be cloned with the vectors. Alternatively, the cleved EcoR1 adaptors can be removed with a small nucleotide removing kit, In this case, there is no need to dephosphorylate the SmaI cut-ends of the vectors. Clones carrying inserts can be recognized by blue/white selection. The symbol $(\diamond)$ represents sequence variation. Please see the text for further details. 


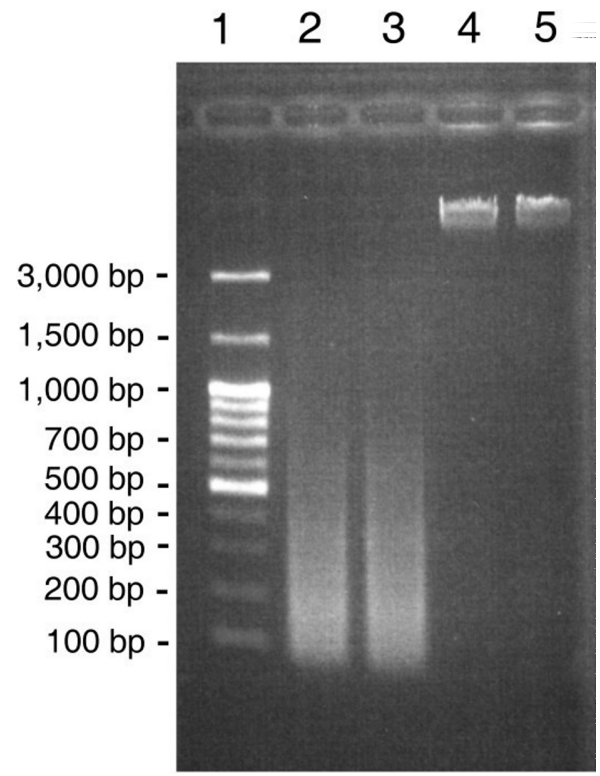

Fig. 2. Analysis of chromosomal DNA fragments generated by Tsp509I digestion. Hep G2 and Chang liver chromosomal DNA were digested with Tsp509I and analyzed by $2 \%$ agarose gel electrophoresis. Lane 1, marker DNA (100 bp DNA ladders, Geneaid, Taoyuan, Taiwan); lane 2, Tsp509I-cleaved Hep G2 chromosome DNA; lane 3, Tsp509I-cleaved Chang liver chromosome DNA; lane 4, Hep G2 chromosome DNA; lane 5, Chang liver chromosome DNA.

generated by $\mathrm{T} 7$ endonuclease I at the sites of SNPs.

Each DNA fragment possesses two EcoR1-compatible ends. After having been treated with $\mathrm{T} 7$ endonuclease I and nuclease S1, each DNA fragment containing SNP possesses an EcoR1-compatible end and a blunt end near the site of the SNP; on the other hand, each normal DNA fragment contains only two EcoR1-compatible ends. This makes it possible to clone the SNP fragments differentially. To achieve this, the pUC 19 vector was cut with SmaI, dephosphorylated by CIP, and cleaved with EcoR1. These treatments create a pUC 19 vector containing a phosphorylated EcoR1-compatible cohesive end and a dephosphorylated blunt end. Thus, the DNA fragments containing SNPs can be cloned with the SmaI-CIPEcoR1-treated pUC 19 vectors; while the DNA fragments of the normal genes cannot be cloned with the vectors.

T4 DNA polymerase can remove protruding singlestranded $3^{\prime}$ termini with its $3^{\prime}$ to $5^{\prime}$ exonucleolytic activity and fills in recessed 3'-hydroxyl termini with its $5^{\prime}$ to $3^{\prime}$ polymerizing activity; therefore T4 DNA polymerase treatment generates ligatable blunt DNA ends (Sambrook et al., 1989). Thus, the DNA fragments were treated with T4 DNA polymerase to repair frayed termini generated by nuclease S1. Before cloning, EcoR1 adaptors in the duplex DNA fragments were cleaved by Tsp509I digestion. Because the blunt ends of the EcoR1 adaptors are dephosphorylated, the free EcoR1 adaptors cannot be cloned with the SmaI-CIP$E c o$ R1-treated vectors. Since cloned insert fragment that

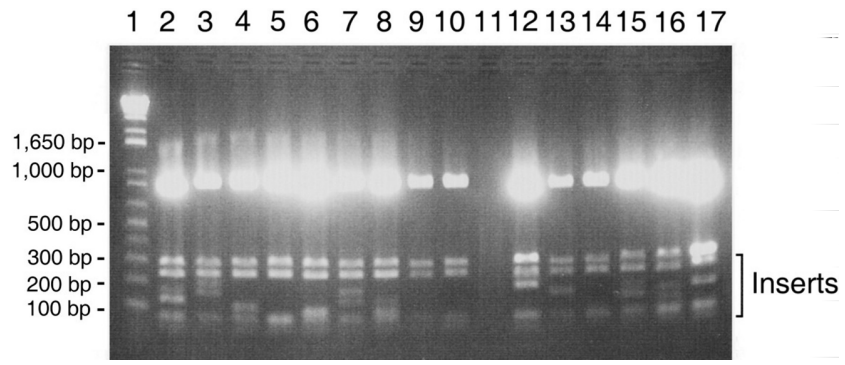

Fig. 3. Analysis of inserts of some of the isolated clones by $2 \%$ agarose gel electrophoresis. Lane 1, marker DNA (1-kb plus DNA ladders, Invitrogen); lanes 2 16, DNA fragments of pUC 19 plasmids digested with HindIII and Tsp509I. pUC 19 plasmids were isolated from the bacterial cultures of the white colonies of the heteroduplex samples. Bracket indicates inserts.

smaller than $15 \mathrm{bp}$ is difficult to identify which gene it belongs. And although the free EcoR1 adaptors are unable to be cloned with the vectors, the EcoR1 ends of these adaptors still can ligate into the EcoR1 ends of the vectors. Thus, removing the free $E c o \mathrm{R} 1$ adaptors with commercial nucleotide removing kit that removes nucleotides smaller than $15 \mathrm{bp}$, and then reducing the volume of the DNA sample by ethanol precipitation before ligation, should be able to increase the cloning efficiency of the duplex DNA fragments. Because the purpose of the dephosphorylation of the blunt ends of the cloning vector is to inhibit the cloning of the free EcoR1 adaptors. If the free EcoR1 adaptors are removed with a small nucleotide removing kit, then there is no need to dephosphorylate the blunt ends of the cloning vectors. The phosphorylation in the blunt ends of the vectors also can increase the efficiency of ligation. Clones containing inserts can be recognized by blue/ white selection. Restriction enzyme analyses of some of the plasmids isolated from the white clones of the heteroduplex DNA samples are shown in Fig. 3. The sizes of these cloned inserts ranged from about 20 to $350 \mathrm{bp}$.

Various doses of $\mathrm{T} 7$ endonuclease I (3, 7.5, and $15 \mathrm{U} /$ reaction) and nuclease $\mathrm{S} 1$ (10, 22, and $35 \mathrm{U} /$ reaction) and different enzyme incubation times were tested. The most optimum condition was with $7.5 \mathrm{U} /$ reaction T7 endonuclease I followed by $22 \mathrm{U} /$ reaction nuclease $\mathrm{S} 1$ treatment. The condition of $7.5 \mathrm{U} /$ reaction $\mathrm{T} 7$ endonuclease I digestion followed by $22 \mathrm{U} /$ reaction nuclease $\mathrm{S} 1$ treatment were independently repeated 3 times, and all replicates produced satisfactory positive results. The numbers of white colonies of the heteroduplex DNA samples were significantly higher than those of the control homoduplex DNA samples. Numbers of white colonies were 5,617 \pm 353 (mean \pm standard deviation (SD)) and $636 \pm 87$ for heteroduplex and control homoduplex DNA samples, respectively. Clones isolated from the homoduplex control samples may reflect sequence variations (i.e. gene polymorphisms and repetitive sequences) of genes in a cell line.

Thirty isolated clones were sequenced and sequences were identified by BLAST in NCBI. Seven sequences belong to 


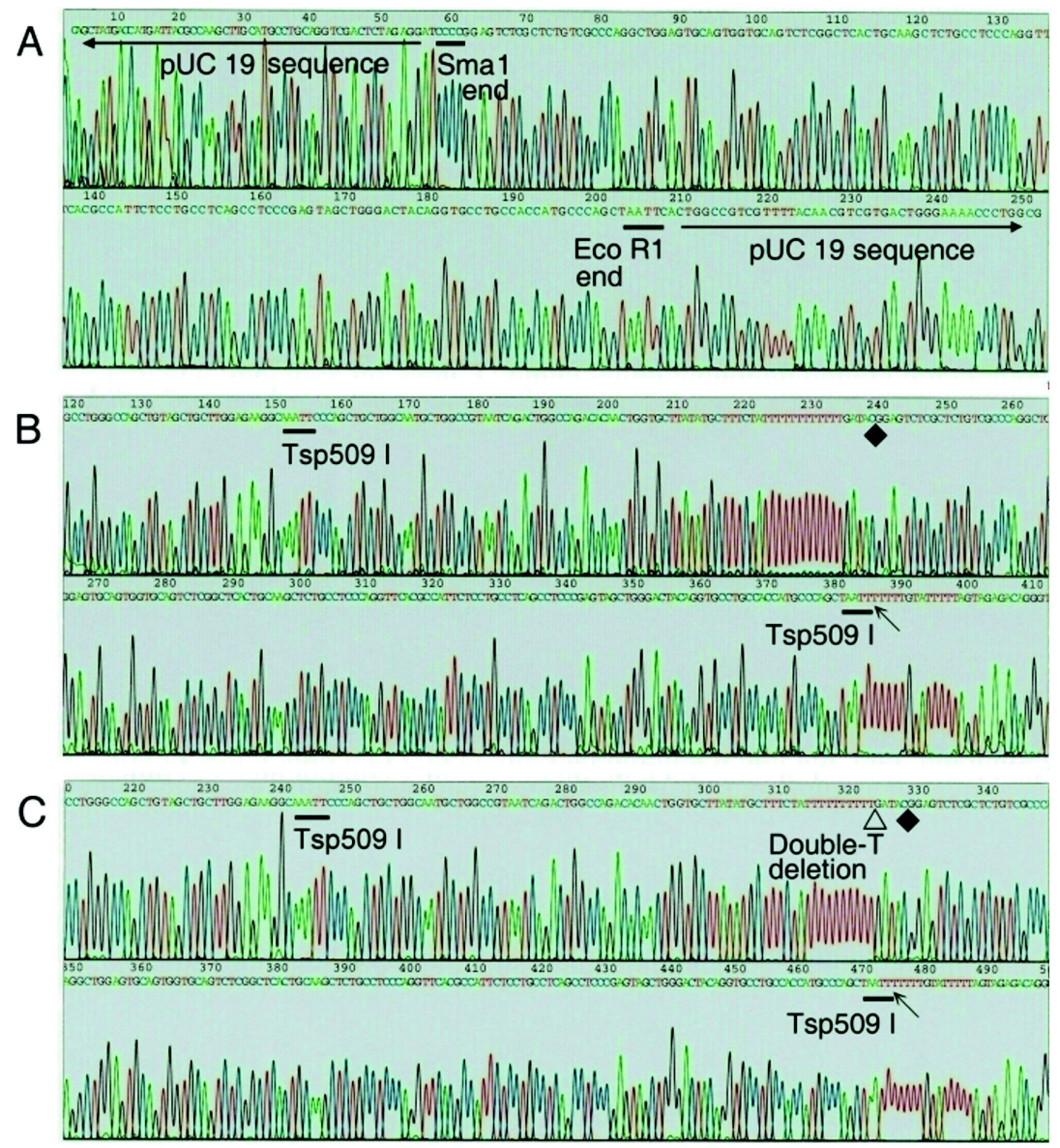

Fig. 4. Comparisons of the clone 16 insert sequence (A) and the PCR-amplified Chang liver (B) and Hep G2 (C) chromosomal DNA sequences that covering the region of the clone 16 insert sequence. The SmaI end and the EcoR1 end of the pUC 19 vector, and the Tsp509I recognition sequences in the Hep G2 and the Chang liver PCR sequences are indicated. The Tsp509I sites of the PCR product sequences that can be ligated into the EcoR1 cloning site of the pUC 19 vector are indicated by arrows. The site of the double-T deletion in the Hep G2 chromosomal PCR sequence is indicated by the symbol $(\Delta)$. The sites of the "differential cloning end" in the Hep G2 and the Chang liver chromosomal PCR sequences are indicated by the symbol $(\diamond)$. Please see the text for further details.

repetitive sequences. There are many repetitive sequences in the human genome. It is difficult to verify SNPs in repetitive sequences, because PCR amplification of a repeat region often produces multiple products. The sequences of three isolated clones were compared with their corresponding Hep G2 and Chang liver chromosomal DNA PCR product sequences to validate the capability of this method in the isolation of sequence variations between tumor and normal cells. All of the Hep G2 chromosomal DNA PCR product sequences analyzed possess SNPs near the sites corresponding to the "differential cloning end" of the inserts of the isolated clones. Because of space limitations, only clone 16 and its corresponding Hep G2 and Chang liver chromosomal DNA PCR product sequences are shown in here to describe the capability of this method in the cloning of SNP sequences.

The clone 16 was isolated from the heteroduplex DNA sample, and its sequence is shown in Fig. 4A. Clone 16 contains a 145-bp insert, and the sequence of this insert is identical to bases 107,640 to 107,785 of the RP11-137L15 gene (GenBank accession no. AC023991). Hep G2 and Chang liver chromosome DNA regions covering the sequence of the clone 16 insert were amplified by PCR. The amplified 621-bp PCR product corresponds to bases 107,439 to 108,060 of the RP11-137L15 gene. DNA sequencing analysis showed that the sequences of the Hep G2 and the Chang liver PCR products were identical except that there was a double-T deletion in the Hep G2 PCR product sequence. The site of this double-T deletion corresponds to base 107,791 of the RP11-137L15 gene, and this site is 5 bases toward the "differential cloning end" which is located at base 107,786 the gene. Each Hep G2 and Chang liver PCR product sequence possesses two Tsp509I recognition sites (Fig. 4 B and C). In the RP11-137L15 gene sequence, there are also two Tsp509I recognition sites in bases 107,640 and 107,873. The two Tsp509I sites in bases 107,640 and 107,873 of the RP11-137L15 gene provided the EcoR1-compatible end for cloning of the SNPs that located from bases 107,640 to 107,873 of the gene.

The 145-bp insert was ligated to the EcoR1 end of the pUC 
19 vector with its Tsp509I end, and was ligated to the SmaI end of the pUC 19 vector with its "differential cloning end". The "differential cloning end" was the site that T7 endonuclease I recognized and cut, and which was near the SNP site of the sequence. These results demonstrate the success of this method in the cloning of SNP sequences between cells, and also demonstrate that the sites of SNPs can be localized to within 6 nucleotides.

The average density of SNPs was estimated 1 per $1.9 \mathrm{~kb}$ in the human genome (The International SNP Map Working Group, 2001). The SNPs are not evenly distributed in the human genome: $90 \%$ of contiguous $20-\mathrm{kb}$ windows contain one or more SNPs, as do $63 \%$ of 5-kb windows and $28 \%$ of $1-$ $\mathrm{kb}$ windows, and $4 \%$ of genome sequence fall in gaps between SNPs of $>80 \mathrm{~kb}$ (The International SNP Map Working Group, 2001). It should be noted that the average density of SNPs are calculated based on SNP data collected from multiple individuals, hence the average density of SNPs between an affected individual and a comparable normal individual, or between the tumor and the normal cells (or tissues) of a same individual, must be much less than 1 per 1.9 $\mathrm{kb}$. Thus, the differential cloning method should be superior to method by randomly sequencing the plasmids of a wholegenome library for identifying sequence differences between tumor and normal cells by most ordinary laboratories. Since there will be a high percentage of plasmids in the wholegenome library that dont contain sequence differences, and most laboratories dont have sufficient financial support to sequencing all the clones of both the tumor cell and the normal cell whole-genome libraries.

The numbers of SNPs identified are approaching 3 million; nevertheless identification of new SNPs from diverse kinds of diseases will still be helpful for disease gene discovery. Moreover, analyzing the sequence differences between the tumor cells and the normal cells of a same individual at a large-scale should be important for the discovery of oncogenes. This method needs no expensive or complex equipment, and the techniques of the method should be easy for most researchers. Thus, this method may be able to facilitate the discovery of genetic factors that associated with cancer formation and progression.

Acknowledgments We thank Mr. Daniel Chamberlin and Mr. Tung-Yang Hung for editorial assistance. The expenses of this work were defrayed by the corresponding author.

\section{References}

Becker, N., Nieters, A. and Rittgen, W. (2003) Single nucleotide polymorphism-disease relationships: statistical issues for the performance of association studies. Mutat. Res. 525, 11-18.

Cantor, C. R. (1999) Pharmacogenetics becomes pharmacogenomics: wake up and get ready. Mol. Diagn. 4, 287-288.

Chaudhry, M. and Weinfeld, M. (1995) Induction of double-strand breaks by $\mathrm{S} 1$ nuclease, mung bean nuclease and nuclease $\mathrm{P} 1$ in DNA containing abasic sites and nicks. Nucleic Acids Res. 23, 3805-3809.

Chen, X. and Sullivan, P. F. (2003) Single nucleotide polymorphism genotyping: biochemistry, protocol, cost and throughput. Pharmacogenomics J. 3, 77-96.

Goodstadt, L. and Ponting, C. P. (2001) Sequence variation and disease in the wake of the draft human genome. Hum. Mol. Genet. 10, 2209-2214.

Elahi, E., Kumm, J. and Ronaghi, M. (2004) Global genetic analysis. J. Biochem. Mol. Biol. 37, 11-27.

Kelley, W. and Stump, K. (1979) A rapid procedure for isolation of large quantities of Escherichia coli DNA polymerase I utilizing a lambdapol A transducing phage. J. Biol. Chem. 254, 3206-3210.

Kleff, S. and Kemper, B. (1988) Initiation of heteroduplex-loop repair by T4-encoded endonuclease VII in vitro. EMBO J. 7, 1527-1535.

Kosak, H. and Kemper, B. (1990) Large-scale preparation of T4 endonuclease VII from over-expressing bacteria. Eur. J. Biochem. 194, 779-784.

Kwok, P. (2003) Single Nucleotide Polymorphisms: Methods and Protocols, Humana Press, New Jersey, USA.

Jiang, M. C. and Liao, C. F. (2004) CAS overexpression inhibits the tumorigenicity of HT-29 colon cancer cells. J. Exp. Clin. Cancer Res. 23, 325-332.

Mashal, R., Koontz, J. and Sklar, J. (1995) Detection of mutations by cleavage of DNA heteroduplexes with bacteriophage resolvases. Nat. Genet. 23, 177-183.

Mir, K. U. and Southern, E. M. (200) Sequence variation in genes and genomic DNA: methods for large-scale analysis. Аnnu. Rev. Genomics Hum. Genet. 1, 329-360.

Nelson, M. R., Marnellos, G., Kammerer, S., Hoyal, C. R., Shi, M. M., Cantor, C. R. and Braun, A. (2004) Large-scale validation of single nucleotide polymorphisms in gene regions. Genome Res. 14, 1664-1668.

Parkinson, M. and Lilley, D. (1997) The junction-resolving enzyme T7 endonuclease I: quaternary structure and interaction with DNA. J. Mol. Biol. 270, 169-178.

Parsons, C., Kemper, B. and West, S. (1990) Interaction of a fourway junction in DNA with T4 endonuclease VII. J. Biol. Chem. 265, 9285-9289.

Sambrook, J., Fritsch, E. and Maniatis, T. (1989) Molecular Cloning, 2nd ed. Cold Spring Harbor Laboratory Press, New York, USA.

Sinden, R. R. and Wells, R. D. (1992) DNA structure, mutations, and human genetic disease. Curr. Opin. Biotechnol. 3, 612-622.

Solaro, P., Birkenkamp, K., Pfeiffer, P. and Kemper, B. (1993) Endonuclease VII of phage T4 triggers mismatch correction in vitro. J. Mol. Biol. 230, 868-877.

The International HapMap Consortium (2003) The international HapMap project. Nature 426, 789-796

The International SNP Map Working Group (2001) A map of human genome sequence variation containing 1.42 million single nucleotide polymorphisms. Nature 409, 928-933.

Youil, R., Kemper, B. and Cotton, R. (1995) Screening for mutations by enzyme mismatch cleavage with T4 endonuclease VII. Proc. Natl. Acad. Sci. USA 92, 87-91. 